\title{
Efficiency of pH-Sensitive Fusogenic Polymer-Modified Liposomes as a Vaccine Carrier
}

\author{
Shinobu Watarai, ${ }^{1}$ Tana Iwase, ${ }^{1}$ Tomoko Tajima, ${ }^{1}$ Eiji Yuba, ${ }^{2}$ and Kenji Kono ${ }^{2}$ \\ ${ }^{1}$ Division of Veterinary Science, Graduate School of Life and Environmental Sciences, Osaka Prefecture University, Izumisano, \\ Osaka 598-8531, Japan \\ ${ }^{2}$ Department of Applied Chemistry, Graduate School of Engineering, Osaka Prefecture University, Sakai, Osaka 599-8531, Japan
}

Correspondence should be addressed to Shinobu Watarai; swatarai@vet.osakafu-u.ac.jp

Received 11 December 2012; Accepted 30 December 2012

Academic Editors: A. Shikanov, Y.-C. Tyan, and M.-H. Yang

Copyright (C) 2013 Shinobu Watarai et al. This is an open access article distributed under the Creative Commons Attribution License, which permits unrestricted use, distribution, and reproduction in any medium, provided the original work is properly cited.

\begin{abstract}
The usefulness of $\mathrm{pH}$-sensitive fusogenic polymer-(succinylated poly(glycidol)-(SucPG-) modified liposomes as a vaccine carrier in the induction of immune responses was evaluated. Mice were intraperitoneally immunized with ovalbumin- (OVA-) containing SucPG-modified liposomes. After immunization, significant OVA-specific antibodies were detected in the serum. When sera were analyzed for isotype distribution, OVA-specific IgG1 antibody responses were noted in mice immunized with OVA-containing polymer-unmodified liposomes, whereas immunization with OVA-containing SucPG-modified liposomes resulted in the induction of OVA-specific IgG1, IgG2a, and IgG3 Ab responses. In spleen lymphocytes from mice immunized with OVA-containing SucPGmodified liposomes, both IFN- $\gamma$-(Th1-type-) and IL-4-(Th2 type-) specific mRNA were detected. Moreover, substantial production of IFN- $\gamma$ and IL- 4 was demonstrated in spleen cells from OVA-containing SucPG-modified liposomes in vitro. These results suggest that the $\mathrm{pH}$-sensitive fusogenic polymer-(SucPG-) modified liposomes would serve effectively as an antigen delivery vehicle for inducing Th1 and Th2 immune responses.
\end{abstract}

\section{Introduction}

Immune mechanisms that control diseases include mainly the induction of neutralizing antibodies (humoral immunity) and generation of $\mathrm{T}$ cells (cell-mediated immunity), including $\mathrm{CD} 4^{+}$helper (Th) and $\mathrm{CD} 8^{+}$cytotoxic (cytotoxic $\mathrm{T}$ lymphocyte) responses $[1,2]$. The success of vaccines depends on two key aspects: identification of specific antigenic targets and the ability to evoke a strong and appropriate immune response. In addition, efficient vaccination strategies have been desired for overcoming new pathogens and for evolution of resistance of microorganisms. Thus, new adjuvants and carriers are essential to this aim, and efficient vaccine delivery systems have been required for the achievement of protective immunity.

Bilayer vesicles composed of amphiphilic phospholipids (liposomes) have been used as delivery systems for a wide variety of biologically active substance to specific tissues and have also been used as immunological adjuvants to enhance the immune response to several bacterial and viral antigens [3]. In particular, since the liposome-entrapped materials are protected from enzymatic attack until they reach the target sites, the potential usefulness of liposomes as carriers and adjuvants for developing topical and mucosal vaccines has attracted considerable interests during the last few years [4]. Their potential as adjuvants has been demonstrated in several studies, in which the use of liposome-associated antigens resulted in protective immunity [5-14]. From these previous studies, it emerges that the adjuvant effect of the liposomes depends on their physicochemical properties and may be related to prolonged release and protection of encapsulated antigen against the environment and enhanced uptake by the dendritic cells (DCs). It is generally accepted that cationic liposomes are more potent adjuvants compared to anionic and neutral liposomes [14]. Their adjuvant effect has been attributed to several mechanisms, such as nonspecific cell 
damage (inducing inflammation) at the site of injection, formation of an antigen depot, and improved antigen uptake by DCs through electrostatic interaction between the cationic liposomes and negatively charged groups on the surface of DCs. However, effective delivery of antigenic proteins into cytosol of DCs is important to induce protective immunity. Thus far, numerous attempts have been undertaken to achieve delivery of antigens into the DC's cytosol [15-17]. These nanoparticles might be taken up by DC via endocytosis and enhance the transfer of their encapsulated antigen molecules from endosome and/or lysosome to cytosol by destabilization of the membranes of these acidic compartments through hydrophobic or electrostatic interactions $[16,17]$. One of the most effective strategies for efficient introduction of antigenic proteins into cytosol of DC would be to use membrane fusion for liposomes. To date, viral fusion proteins have been used frequently to provide liposomes with fusion ability $[18,19]$. Indeed, viral fusion protein-incorporated liposomes have been used to introduce encapsulated antigenic OVA into DC's cytosol and induced efficient cellular immunity $[18,19]$. However, viral proteins might provoke unexpected immune responses. Therefore, the use of synthetic carriers might be preferred for the delivery of antigens into DCs.

To establish effective vaccine delivery system for the induction of protective immunity, we have developed $\mathrm{pH}$ sensitive liposomes, which generate fusion ability under weakly acidic conditions, by surface modification of liposomes with $\mathrm{pH}$-sensitive fusogenic polymer having carboxyl groups, such as succinylated poly(glycidol) (SucPG) [20]. This $\mathrm{pH}$-sensitive fusogenic liposomes encapsulating ovalbumin (OVA) could introduce their contents efficiently into the cytosol of dendritic cells [20]. However, relatively little data on their potential vaccine carrier is inconclusive.

To know the usefulness of $\mathrm{pH}$-sensitive fusogenic polymer-modified liposomes as a vaccine carrier, OVA-containing SucPG-modified liposomes were intraperitoneally inoculated to mice, and immune responses were evaluated. We provide here evidence for the induction of strong antigenspecific Th2 (humoral) and Th1 (cell-mediated) immunity.

\section{Methods}

2.1. Materials. Dipalmitoylphosphatidylcholine (DPPC), dioleoylphosphatidylethanolamine (DOPE), monophosphoryl lipid A (MPL), and ovalbumin (OVA) (SIGMA) were commercial products. Succinylated poly(glycidol) (SucPG) was prepared as previously reported [21, 22]. Molar percentages of glycidol/carboxylated glycidol/ndecylamine-attached units in the resultant SucPG polymer were determined by ${ }^{1} \mathrm{H}$ NMR to be $18 / 74 / 8$ and $9 / 89 / 11$, respectively [20].

2.2. Animals. Female BALB/c mice (6 weeks old) were purchased from Charles River Japan, Tokyo, Japan. Mice were maintained according to the Standards Relating to the Care and Management of Experimental Animals of Japan. The experiments were carried out in accordance with the guidelines for animal experimentation of Osaka Prefecture University.
2.3. Preparation of Liposomes. Polymer-(SucPG-) modified liposomes that entrap OVA were prepared by the following method. DPPC ( $4 \mu \mathrm{mol})$, DOPE $(4 \mu \mathrm{mol})$, MPL $(16 \mu \mathrm{g})$, and SucPG polymer (lipids/polymer $=7 / 3, \mathrm{w} / \mathrm{w}$ ), each dissolved in an organic solvent, were mixed in a conical flask. The lipids were dried on a rotary evaporator, and left to stand for $30 \mathrm{~min}$ in a high vacuum in a desiccator. After the addition of $1 \mathrm{~mL}$ of PBS containing OVA $(5 \mathrm{mg} / \mathrm{mL})$ and the incubation at an appropriate temperature for $3 \mathrm{~min}$, the lipid film was dispersed by vigorous vortexing. Any unencapsulated OVA was removed by repeated centrifuging at $14,000 \times \mathrm{g}$ for $20 \mathrm{~min}$ at $4^{\circ} \mathrm{C}$ in PBS, and the resulting liposome suspension was used for immunization.

Polymer-unmodified liposomes that entrap OVA were prepared from lipid mixture solution containing DPPC (4 $\mu \mathrm{mol})$, DOPE $(4 \mu \mathrm{mol})$, and MPL $(16 \mu \mathrm{g})$ as stated above.

The amount of OVA entrapped in liposomes was determined by the following method. Ninety $\mu \mathrm{L}$ of isopropyl alcohol was added to a $10 \mu \mathrm{L}$ suspension of liposomeentrapped OVA (at 3-fold dilution in PBS), followed by vortex mixing. The protein concentration of the resulting solutions was determined using a Bio-Rad protein assay kit (Bio-Rad Laboratories), with bovine plasma gamma globulin used as a standard.

2.4. Immunization of Mice. Mice were divided into 3 groups (5 mice per a group). Each group was intraperitoneally immunized as follows: group I, OVA alone $(100 \mu \mathrm{g}$ protein $/ 100 \mu \mathrm{L}$ into peritoneal cavity); group II, polymer-unmodified liposomes that entrap OVA $(100 \mu \mathrm{g}$ protein $/ 100 \mu \mathrm{L}$ into peritoneal cavity); group III, SucPG-modified liposomes that entrap OVA $(100 \mu \mathrm{g}$ protein $/ 100 \mu \mathrm{L}$ into peritoneal cavity). Two weeks later, mice were boosted with the same immunogen at an equivalent dose. Seven days after secondary immunization, the mice were killed and sera and spleens were harvested. Sera and spleen collected were used for antibody assay and RNA isolation, respectively. Spleen cells were isolated from mice in group III as described previously [23] and used for cytokine measurements.

2.5. Antibody Assay. OVA was diluted with PBS (10 $\mu \mathrm{g}$ protein $/ \mathrm{mL}$ ) and dispensed in $50 \mu \mathrm{L} /$ well into a 96-well microtiter plate (ASAHI TECHNO GLASS), followed by leaving overnight at $4^{\circ} \mathrm{C}$. The plates were washed 5 times with PBS containing $0.1 \%$ Tween 20 (washing solution). The wells were treated with $100 \mu \mathrm{L}$ of PBS containing $1 \%$ BSA (solution A), incubated at $37^{\circ} \mathrm{C}$ for $60 \mathrm{~min}$ to block nonspecific binding, and then washed 5 times with the washing solution. After that, $50 \mu \mathrm{L}$ of sera diluted with solution A were added to each well. The plates were incubated for $60 \mathrm{~min}$ at $37^{\circ} \mathrm{C}$ and washed 5 times with the washing solution, and then $50 \mu \mathrm{L}$ of horseradish peroxidaselabeled anti-mouse $\operatorname{IgA}(1: 2,000$ dilution in solution $\mathrm{A}$; American Qualex), IgG (1:2,000 dilution in solution A; American Qualex), IgE (1:2,000 dilution in solution A; Bethyl Laboratories), IgG1 (at 1:1,000 dilution in solution A; Zymed Laboratories), IgG2a (at 1:1,000 dilution in solution A; Zymed Laboratories), or IgG3 (at 1:1,000 dilution in solution A; Zymed Laboratories) solution was added as the 
TABLE 1: RT-PCR primers used in this study.

\begin{tabular}{|c|c|}
\hline Gene & Primer sequences \\
\hline IFN- $\gamma$ sense & $5^{\prime}$-TGCATCTTGGCTTTGCAGCTCTTCCTCATGGC-3' \\
\hline IFN- $\gamma$ antisense & $5^{\prime}$-TGGACCTGTGGGTTGTTGACCTCAAACTTGGC-3' \\
\hline \multicolumn{2}{|c|}{ Product: 365 bp GenBank M28621 } \\
\hline IL4 sense & 5'-CCAGCTAGTTGTCATCCTGCTCTTCTTTCTCG-3' \\
\hline IL4 antisense & $5^{\prime}$-CAGTGATGTGGACTTGGACTCATTCATGGTGC-3' \\
\hline \multicolumn{2}{|c|}{ Product: 357 bp GenBank M25892 } \\
\hline G3PDH sense & $5^{\prime}$-ACCACAGTCCATGCCATCAC-3' \\
\hline G3PDH antisense & $5^{\prime}$-TCCACCACCCTGTTGCTGTA- $3^{\prime}$ \\
\hline \multicolumn{2}{|c|}{ Product: 452 bp GenBank M32599 } \\
\hline
\end{tabular}

second antibody. Following incubation for $60 \mathrm{~min}$ at $37^{\circ} \mathrm{C}$, the plates were washed 5 times with the washing solution, and $100 \mu \mathrm{L}$ of o-phenylenediamine dihydrochloride substrate solution (Sumitomo ELISA Color Reagent Kit; Sumitomo Bakelite) was reacted for $15 \mathrm{~min}$ at room temperature. The enzyme reaction was stopped by adding a stopping solution (Sumitomo ELISA Color Reagent Kit), and absorbance at $490 \mathrm{~nm}$ was measured with a microplate reader (Model 450, Bio-Rad Laboratories). Antibody titers are represented as the reciprocal of endpoint dilution exhibiting an optical density more than 2.5 times that of the background.

2.6. RNA Isolation from Spleen and Cytokine RT-PCR. Total RNA was extracted from homogenized spleen tissue using TRIzol reagent (GIBCO-BRL) according to the manufacturer's instruction. The final RNA pellet was resuspended with diethylpyrocarbonate-treated distilled water, and absorbance at $260 \mathrm{~nm}$ was measured. Five micrograms of RNA were used for cDNA synthesis using SuperScript II RNase $\mathrm{H}^{-}$reverse transcriptase and oligo- $\mathrm{dT}_{(12-18)}$ primer (GIBCO-BRL), according to the manufacturer's instruction. Primers used are shown in Table 1. PCR was performed for each cytokine gene in a $50 \mu \mathrm{L}$ reaction mixture containing $1 \mu \mathrm{L}$ of the cDNA, $10 \mathrm{pmol}$ of each primer, $0.2 \mathrm{mM} \mathrm{dNTP}$ mixture, 1.5 units of Taq DNA Polymerase (GIBCO-BRL), $1.5 \mathrm{mM} \mathrm{MgCl}_{2}, 20 \mathrm{mM}$ Tris- $\mathrm{HCl}$ (pH 8.4), and $50 \mathrm{mM} \mathrm{KCl}$ with 5 min denaturation at $94^{\circ} \mathrm{C}$ followed by 35 cycles consisting of $45 \mathrm{sec}$ denaturation at $94^{\circ} \mathrm{C}, 45 \mathrm{sec}$ annealing at $60^{\circ} \mathrm{C}$, and $2 \mathrm{~min}$ extension at $72^{\circ} \mathrm{C}$. The final extension was $7 \mathrm{~min}$. To rule out contamination of DNA in the RNA preparation, cDNA was prepared by the same procedure without the addition of reverse transcriptase, and PCR was performed. As negative control, water was used as template and as a positive control a cDNA prepared from RNA extracted from PWMstimulated mouse spleen cells was used. The PCR products were electrophoresed through a $2 \%$ agarose gel and stained with ethidium bromide.

2.7. Cytokine Measurements. Spleen cells from nontreated control mice and mice in group III were cultured at a density of $1 \times 10^{6}$ cells $/ \mathrm{mL}$ with $5 \mu \mathrm{g} / \mathrm{mL}$ of OVA to detect antigen-specific $\mathrm{T}$ cell-derived cytokine production. Culture supernatants were collected 5 days after incubation, and the levels of Th1 and Th2 cytokines (IFN- $\gamma$ and IL-4) were determined with murine cytokine ELISA kits (R\&D systems, Minneapolis, MN).

2.8. Statistical Analysis. Student's $t$-test was employed in the statistical evaluation of the results.

\section{Resuts}

3.1. Immune Responses in Mice Immunized Intraperitoneally with OVA-Containing SucPG-Modified Liposomes. Mice were administered intraperitoneally with OVA antigen, such as OVA alone (group I), polymer-(SucPG-) unmodified liposomes containing OVA (group II), and SucPG-modified liposomes containing OVA (group III), and antibodies against OVA were evaluated at 14 days after primary immunization.

As shown in Figure 1, in serum from mice receiving OVA alone (group I) and SucPG-unmodified liposomes containing OVA (group II), the production of anti-OVA IgM and IgG antibody was demonstrated, but not IgE antibody. On the other hand, higher-serum IgM and IgG activit against OVA was seen in the mice of group III. IgM and IgG antibody responses against OVA in group III were significantly higher than those in group I (IgM, $P<0.0096 ; \operatorname{IgG}, P<0.0033)$ and group II (IgM, $P<0.021$; IgG, $P<0.019$ ). The serum IgE antibody activities against OVA antigens were not detected in any mouse in group III.

Furthermore, serum $\mathrm{Ab}$ responses were characterized by analyzing the pattern of IgG subclasses present in sera from mice in groups I to III. As shown in Figure 2, only OVAspecific serum IgG1 Ab responses were demonstrated in the serum from mice immunized with OVA alone (group I). On the other hand, the induction of OVA-specific serum IgG1, IgG2a, and IgG3 antibody responses was demonstrated in sera from mice in groups II and III. In particular, the production of anti-OVA IgG1, IgG2a, and IgG3 antibody was significantly enhanced by the intraperitoneal administration of SucPG-modified liposomes containing OVA (group III) than by that of OVA-containing SucPG-unmodified liposomes (group II) (IgG1, $P<0.019$; IgG2a, $P<0.003$; IgG3, $P<0.0091)$.

3.2. Th1 and Th2 Cytokine Production by Spleen Cells from Mice Immunized Intraperitoneally with OVA-Containing SucPG-Modified Liposomes. The induction of OVA-specific 


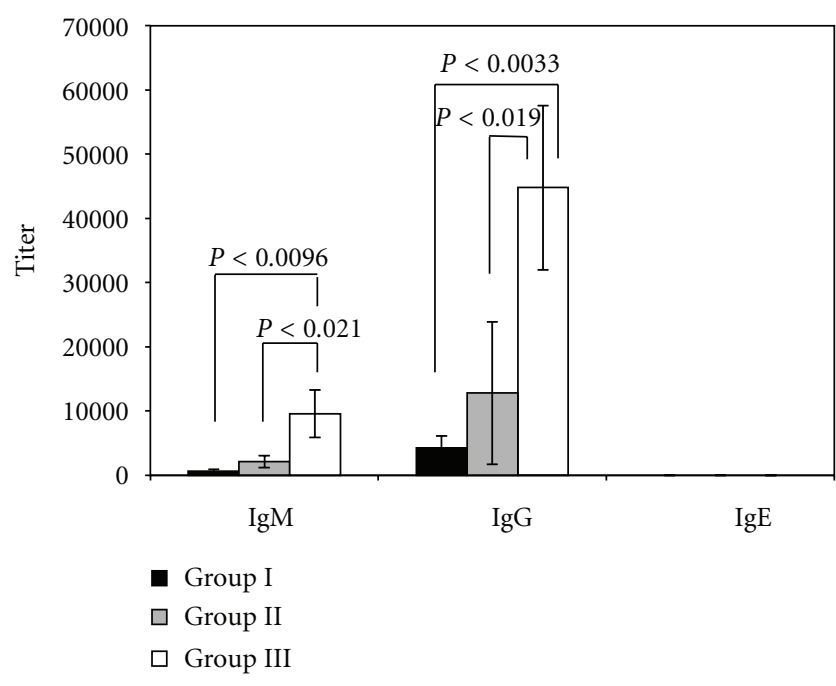

FIGURE 1: Serum anti-OVA antibody responses in mice administered OVA-containing SucPG-modified liposomes. Mice were immunized intraperitoneally with OVA alone (group I) or polymer(SucPG-) unmodified liposomes entrapping OVA (group II) or SucPG-modified liposomes entrapping OVA (group III), and serum antibody titers were determined by ELISA on day 7 following secondary immunization. Results are expressed as the mean \pm SEM in 5 different mice.

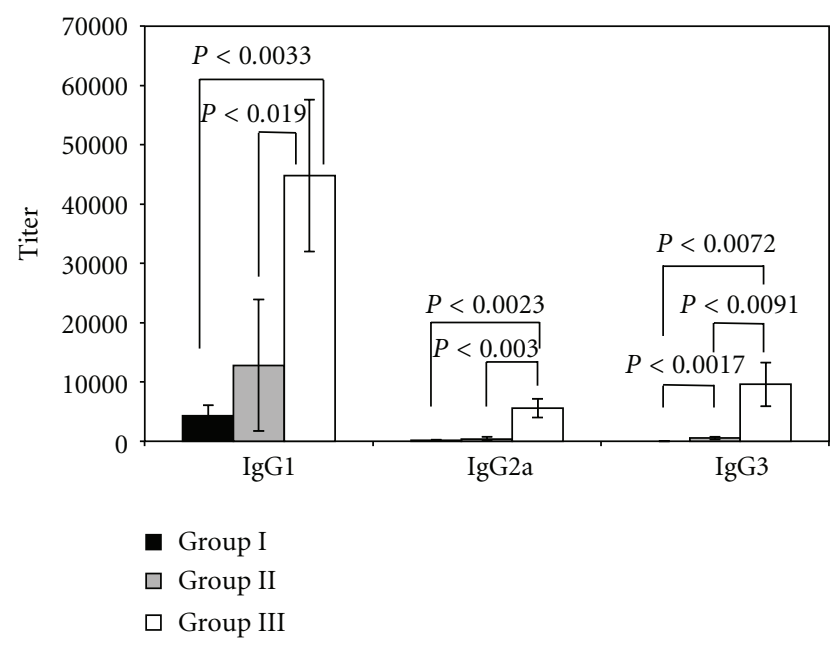

Figure 2: Profiles of OVA-specific IgG antibody subclasses in mice intraperitoneally immunized with OVA-containing SucPGliposomes. Mice were immunized intraperitoneally with OVA alone (group I) or polymer-(SucPG-) unmodified liposomes entrapping OVA (group II) or SucPG-modified liposomes entrapping OVA (group III), and serum antibody titers were measured by ELISA on day 7 following secondary immunization. Results are expressed as the mean \pm SEM in 5 different mice.

serum IgG1, IgG2a, and IgG3 antibody responses by intraperitoneal immunization with OVA-containing SucPG-modified liposomes suggests efficient major histocompatibility complex presentation of the antigen leading to both humoral (IgG1) (Th2) and cell-mediated (IgG2a and IgG3) (Th1) responses (Figure 2). To characterize antigen-specific Th1 and Th2 responses, spleen cells were isolated from mice given SucPG-modified liposomes that entrap OVA (group III) and restimulated with OVA in vitro. Culture supernatants from OVA-stimulated spleen cells were then examined for the presence of Th1 and Th2 cytokines by ELISA. As shown in Figure 3, higher levels of both Th1 (IFN- $\gamma$ ) and Th2 (IL-4) cytokines were detected in the culture supernatant harvest from in vitro OVA-stimulated spleen cells from mice in group III than did spleen cells from nontreated control mice.

3.3. Induction of IFN- $\gamma$ - and IL-4-Specific mRNA in Spleen Cells from Mice Immunized Intraperitoneally with OVAContaining SucPG-Modified Liposomes. The production of Th1-type (IFN- $\gamma$ ) and Th2-type (IL-4) cytokines by spleen cells from mice receiving intraperitoneal OVA-containing SucPG-modified liposomes following in vitro restimulation was confirmed (Figures 3(a) and 3(b)). To confirm this finding at molecular levels, Th1 and Th2 cytokine-specific RT-PCR was performed by using RNA samples extracted from spleen cells of mice intraperitoneally immunized with SucPG-modified liposomes containing OVA. Results are shown in Figure 4. mRNA for Th1-type cytokine, that is, IFN- $\gamma$ (365 bp), and for Th2-type cytokine, that is, IL-4 (357 bp), were expressed in spleen cells from mice given OVA-containing SucPG-modified liposomes intraperitoneally (group III) (Figure 4, lane 1). However, neither IFN$\gamma$ mRNA nor IL-4 mRNA expression was detected in spleen cells from nontreated control mice.

\section{Discussion}

Vaccines have played an important role in disease prevention and have made a substantial contribution to public health. Upon natural infection, it is known that the host responds by inducing both humoral and cellular immunities against the pathogen. However, most of the currently approved vaccines work by inducing humoral immunity [24-26]. For protection against viruses that are highly mutable and frequently escape from antibody-mediated immunity, humoral immunity is insufficient [27-30]. Consequently, the development of vaccines that induce cellular immunity is critical to novel vaccine strategies. Thus, the new adjuvants and carriers are essential to this aim. In particular, efficient vaccine delivery systems have been required for the achievement of protective immunity. Previously, it has been established that liposomes have the applicability as an adjuvant for use in vaccines [3, 31]. In addition, we have demonstrated that liposomes are an effective mucosal antigen-delivery vehicle for the induction of systemic and local immune responses [31, 32]. More recently, we have developed $\mathrm{pH}$-sensitive fusogenic polymer, SucPG-modified liposomes [20]. These liposomes can deliver antigenic proteins into cytosol of dendritic cells [20], suggesting that SucPG-modified liposomes are able to induce both humoral (Th1) and cellular (Th2) immune responses against encapsulated antigens following the administration of the liposomes. In the present study, thus, we used the $\mathrm{pH}$ sensitive fusogenic polymer (SucPG-) modified liposomes as antigen delivery vehicle for the vaccine and evaluated the ability of inducing Th1 and Th2 immune responses. 


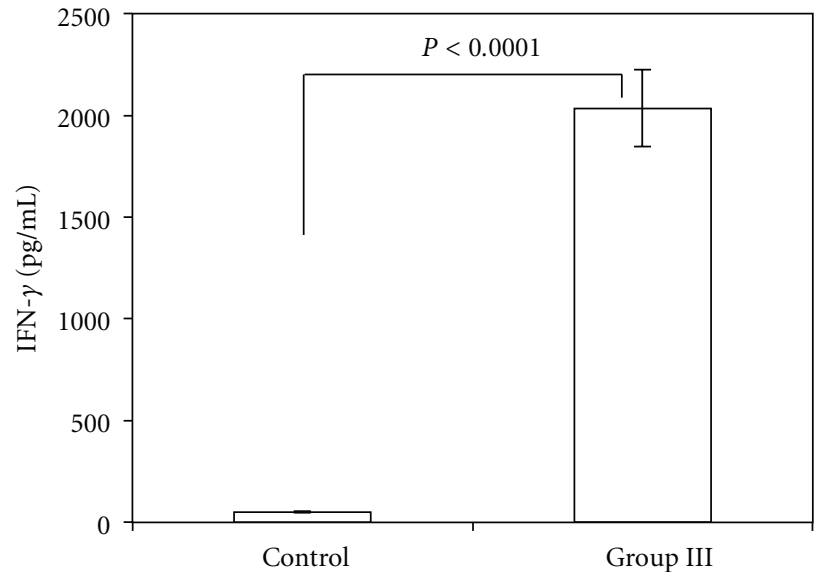

(a)

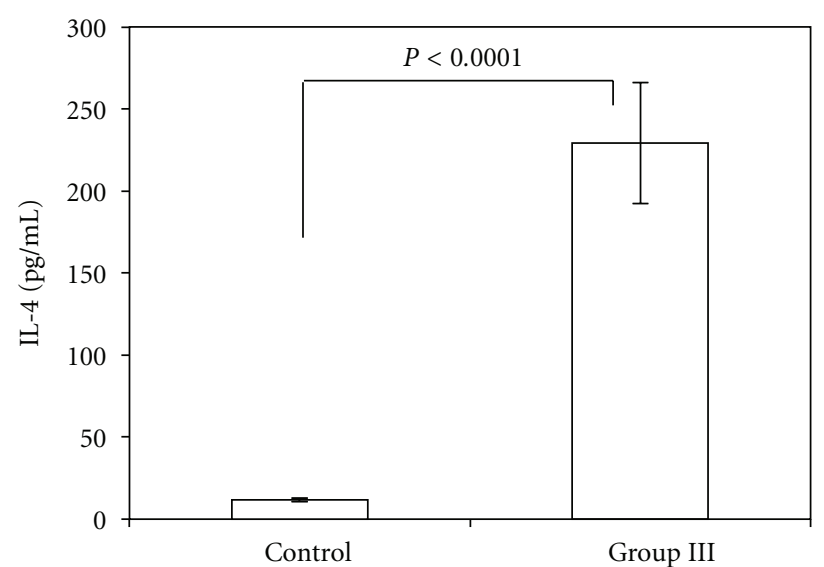

(b)

FIGURE 3: Th1 (IFN- $\gamma$ ) and Th2 (IL-4) cytokine secretion by spleen cells from mice after intraperitoneal administration of OVA-containing SucPG-modified liposomes. Spleen cells were harvested on day 7 after secondary immunization and cultured with OVA for 5 days. Subsequently, culture supernatants were collected for the analysis of cytokine production by ELISA. Values represent the mean \pm SEM of cytokine production by spleen cells of mice in each group (nontreated control mice (Control) and OVA-containing SucPG-modified liposomeimmunized mice (Group III)). (a) IFN- $\gamma$. (b) IL-4.

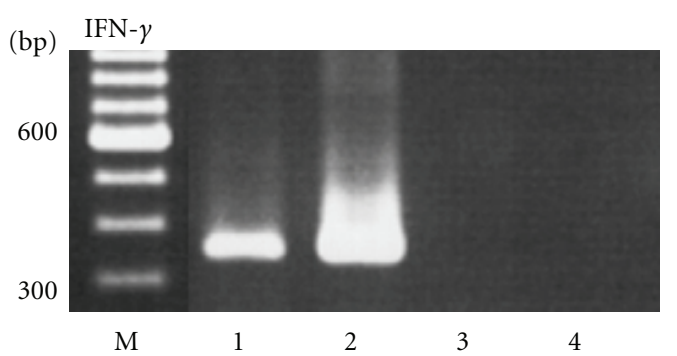

(a)

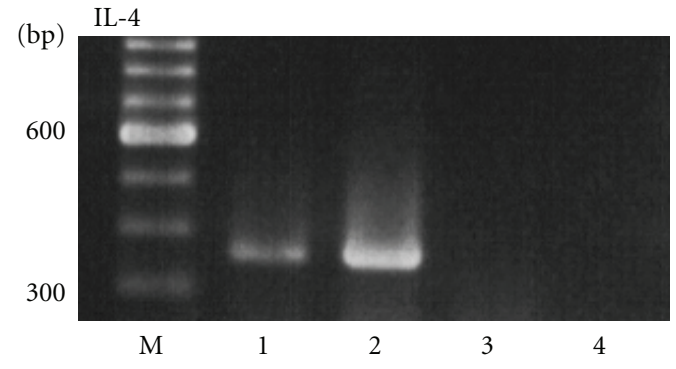

(b)

FIGURE 4: RT-PCR analysis of Th1 and Th2 cytokine-specific mRNA from spleen cells of mice immunized intraperitoneally with OVAcontaining SucPG-modified liposomes. An identical experiment was repeated on three occasions with similar results. M, Marker (100 base ladder). Lane 1, Immunized mice. Lane 2, Positive control. Lane 3, Non-treated control mice. Lane 4, Negative control.

In this study, the intraperitoneal administration of OVAcontaining SucPG-modified liposomes (group III) induced not only good serum IgM antibody responses directed against OVA, but also good serum IgG antibody responses directed against OVA (Figure 1). On the other hand, intraperitoneal immunization with polymer-unmodified liposomes containing OVA (group II) was also able to induce both serum IgM and IgG antibody responses. However, SucPG-modified liposomes containing OVA (group III) induced $\mathrm{Ab}$ responses (IgM and $\operatorname{IgG}$ ) in mice greater than those induced by polymer-unmodified liposomes containing OVA (Figure 1). This indicates that SucPG-modified liposomes act as an effective adjuvant for potentiating $\operatorname{IgM}$ and $\operatorname{IgG}$ antibody responses in the serum when administered by intraperitoneal route and that the adjuvant properties of liposomes can be further enhanced by the inclusion of polymer such as SucPG in liposomes. Furthermore, we evaluated whether polymermodified liposomes containing OVA induce IgE production, because IgE shows detrimental effects, such as allergy. In this study, intraperitoneal immunization with OVA-containing SucPG-modified liposomes did not elicit any IgE production against OVA (Figure 1), suggesting that polymer-modified liposomes might serve as a vaccine candidate without detrimental effects, such as allergic responses.

In the present study, it was shown that intraperitoneal immunization with SucPG-unmodified liposomes containing OVA (group II) and with OVA-containing SucPG-modified liposomes (group III) induced not only antigen-specific IgG1 response, but also IgG2a and IgG3 responses (Figure 2). However, anti-OVA IgG1, IgG2a, and IgG3 antibodies were significantly enhanced by SucPGmodified liposomes containing OVA in comparison to those induced after immunization with OVA-containing SucPGunmodified liposomes (IgG1, $P<0.019$; IgG2a, $P<0.003$; $\operatorname{IgG} 3, P<0.0091$ ) (Figure 2). IgG1 antibody is regulated by Th2-type cytokines, while IgG2a, and IgG3 antibodies are 
regulated by Th1-cytokines [33]. Thus, a higher induction of IgG1, IgG2a and IgG3 antibodies by SucPG-modified liposomes suggests efficient major histocompatibility complex class II presentation of the antigen leading to both humoral (Th2-type) (IgG1) and cell-mediated (Th1-type) (IgG2a and IgG3) responses. Actually, this was corroborated by the production of cytokines IFN- $\gamma$ (Th1) and IL-4 (Th2) (Figure 3), as well as the induction of mRNA for IFN- $\gamma$ and IL- 4 by spleen cells of OVA-containing SucPG-modified liposomeimmunized mice (Figure 4).

The most effective immune response against multiple pathogens involves a combination of both humoral and cellular components. This is even true for some obligate intracellular pathogens $[34,35]$. In general, the immunogenicity of vaccines can be enhanced by the use of adjuvants such as alum (aluminum-based mineral salt) [36]. Alum has been used widely and successfully in many licensed vaccines and has a good track record of safety. It is considered the adjuvant of choice for vaccines against infectious diseases that can be prevented by the humoral immune response $[37,38]$. However, some limitations of alum have been described. Notably, alum is a poor inducer of cell-mediated immunity and $\mathrm{T}$ helper 1 (Th1) responses, which are critical to novel vaccine strategies $[38,39]$. Thus, there is need to develop new adjuvant formulations for use in the development of effective vaccines which can induce both humoral and cellular immunities against the pathogens. We have provided here evidence for induction of strong antigen-specific Th2 and Th1 immune responses. Therefore, a new immunizing method (vaccine) using $\mathrm{pH}$-sensitive fusogenic polymermodified liposomes, such as SucPG-modified liposomes, would clearly be valuable. To our knowledge, this study is the first to evaluate $\mathrm{pH}$-sensitive fusogenic polymer-(SucPG-) modified liposomes for use as a vaccine carrier. This $\mathrm{pH}$ sensitive fusogenic polymer-(SucPG-) modified liposome vaccine would be effective in eliciting protective immunity, thereby facilitating the eradication of the disease.

\section{Conclusions}

In conclusion, the study was carried out to evaluate the usefulness of $\mathrm{pH}$-sensitive fusogenic polymer-modified liposomes as a vaccine carrier. It was confirmed that $\mathrm{pH}$-sensitive fusogenic polymer-(SucPG-) modified liposomes could serve effectively as an antigen delivery vehicle (vaccine carrier) for inducing immune responses and that both humoral (Th2type) and cell-mediated (Th1-type) immunity were induced by intraperitoneal immunization with $\mathrm{pH}$-sensitive fusogenic polymer-(SucPG-) modified liposomes.

In summary, it is expected to use $\mathrm{pH}$-sensitive fusogenic polymer-(SucPG-) modified liposomes as vaccine delivery vehicles (vaccine carrier) for the induction of protective humoral and cell-mediated immunities.

\section{References}

[1] L. Krishman and T. R. Mosmann, "Functional subpopulation of $\mathrm{CD}^{+} \mathrm{T}$ lymphocytes," in T Lymphocyte Subpopulation in
Immunotoxicology, pp. 7-32, John Wiley \& Sons, Chichester, UK, 1998.

[2] T. R. Mosmann and S. Sad, "The expanding universe of T-cell subsets: Th1, Th2 and more," Immunology Today, vol. 17, no. 3, pp. 138-146, 1996.

[3] G. Gregoriadis, "Immunological adjuvants: a role for liposomes," Immunology Today, vol. 11, no. 3, pp. 89-97, 1990.

[4] E. L. Romero and M. J. Morilla, "Topical and mucosal liposomes for vaccine delivery," Wiley Interdisciplinary Reviews: Nanomedicine and Nanobiotechnology, vol. 3, no. 4, pp. 356-375, 2011.

[5] R. L. Gregory, S. M. Michalek, G. Richardson, C. Harmon, T. Hilton, and J. R. McGhee, "Characterization of immune response to oral administration of Streptococcus sobrinus ribosomal preparations in liposomes," Infection and Immunity, vol. 54, no. 3, pp. 780-786, 1986.

[6] L. P. Kahl, R. Lelchuk, C. A. Scott, and J. Beesley, "Characterization of Leishmania major antigen-liposomes that protect $\mathrm{BALB} / \mathrm{c}$ mice against cutaneous leishmaniasis," Infection and Immunity, vol. 58, no. 10, pp. 3233-3241, 1990.

[7] R. Bülow and J. C. Boothroyd, "Protection of mice from fatal Toxoplasma gondii infection by immunization with p30 antigen in liposomes," Journal of Immunology, vol. 147, no. 10, pp. 34963500, 1991.

[8] W. Li, S. Watarai, T. Iwasaki, and H. Kodama, "Suppression of Salmonella enterica serovar Enteritidis excretion by intraocular vaccination with fimbriae proteins incorporated in liposomes," Developmental and Comparative Immunology, vol. 28, no. 1, pp. 29-38, 2004.

[9] T. Irie, S. Watarai, T. Iwasaki, and H. Kodama, "Protection against experimental Aeromonas salmonicida infection in carp by oral immunisation with bacterial antigen entrapped liposomes," Fish and Shellish Immunology, vol. 18, no. 3, pp. 235242, 2005.

[10] A. Rhalem, C. Bourdieu, G. Luffau, and P. Pery, "Vaccination of mice with liposome-entrapped adult antigens of Nippostrongylus brasiliensis," Annales de l'Institut Pasteur. Immunology, vol. 139, no. 2, pp. 157-166, 1988.

[11] D. T. O'Hagan and R. Rappuoli, “Novel approaches to vaccine delivery," Pharmaceutical Research, vol. 21, no. 9, pp. 1519-1530, 2004.

[12] G. F. A. Kersten and D. J. A. Crommelin, "Liposomes and ISCOMs," Vaccine, vol. 21, no. 9-10, pp. 915-920, 2003.

[13] G. Gregoriadis, A. Bacon, W. Caparros-Wanderley, and B. McCormack, "A role for liposomes in genetic vaccination," Vaccine, vol. 20, supplement 5, pp. B1-B9, 2002.

[14] D. Christensen, K. S. Korsholm, P. Andersen, and E. M. Agger, "Cationic liposomes as vaccine adjuvants," Expert Review of Vaccines, vol. 10, no. 4, pp. 513-521, 2011.

[15] T. Akagi, X. Wang, T. Uto, M. Baba, and M. Akashi, "Protein direct delivery to dendritic cells using nanoparticles based on amphiphilic poly(amino acid) derivatives," Biomaterials, vol. 28, no. 23, pp. 3427-3436, 2007.

[16] T. Yoshikawa, N. Okada, A. Oda et al., "Development of amphiphilic $\gamma$-PGA-nanoparticle based tumor vaccine: potential of the nanoparticulate cytosolic protein delivery carrier," Biochemical and Biophysical Research Communications, vol. 366, no. 2, pp. 408-413, 2008.

[17] Y. J. Kwon, S. M. Standley, S. L. Goh, and J. M. J. Fréchet, "Enhanced antigen presentation and immunostimulation of dendritic cells using acid-degradable cationic nanoparticles," Journal of Controlled Release, vol. 105, no. 3, pp. 199-212, 2005. 
[18] J. Kunisawa, T. Nakanishi, I. Takahashi et al., "Sendai virus fusion protein-mediates simultaneous induction of MHC class I/II-dependent mucosal and systemic immune responses via the nasopharyngeal-associated lymphoreticular tissue immune system," Journal of Immunology, vol. 167, no. 3, pp. 1406-1412, 2001.

[19] L. Bungener, K. Serre, L. Bijl et al., "Virosome-mediated delivery of protein antigens to dendritic cells," Vaccine, vol. 20, no. 17-18, pp. 2287-2295, 2002.

[20] E. Yuba, C. Kojima, A. Harada, Tana, S. Watarai, and K. Kono, " $\mathrm{pH}$-sensitive fusogenic polymer-modified liposomes as a carrier of antigenic proteins for activation of cellular immunity," Biomaterials, vol. 31, no. 5, pp. 943-951, 2010.

[21] N. Sakaguchi, C. Kojima, A. Harada, and K. Kono, "Preparation of $\mathrm{pH}$-sensitive poly(glycidol) derivatives with varying hydrophobicities: their ability to sensitize stable liposomes to pH," Bioconjugate Chemistry, vol. 19, no. 5, pp. 1040-1048, 2008.

[22] K. Kono, K. I. Zenitani, and T. Takagishi, "Novel pH-sensitive liposomes: liposomes bearing a poly(ethylene glycol) derivative with carboxyl groups," Biochimica et Biophysica Acta, vol. 1193, no. 1, pp. 1-9, 1994.

[23] S. Watarai, Y. Kushi, R. Shigeto et al., "Production of monoclonal antibodies directed to Hanganutziu-Deicher active gangliosides, $\mathrm{N}$-glycolylneuraminic acid-containing gangliosides," Journal of Biochemistry, vol. 117, no. 5, pp. 1062-1069, 1995.

[24] A. Mark, B. Björkstén, and M. Granström, "ImmunoglobulinEresponsesto diphtheria and tetanus toxoids after booster with aluminium-adsorbed and fluid DT-vaccines," Vaccine, vol. 13, no. 7, pp. 669-673, 1995.

[25] H. Aggerbeck, J. Wantzin, and I. Heron, "Booster vaccination against diphtheria and tetanus in man. Comparison of three different vaccine formulations-III," Vaccine, vol. 14, no. 13, pp. 1265-1272, 1996.

[26] H. D. Nothdurft, T. Jelinek, A. Marschang, H. Maiwald, A. Kapaun, and T. Löscher, "Adverse reactions to Japanese encephalitis vaccine in travellers," Journal of Infection, vol. 32, no. 2, pp. 119-122, 1996.

[27] P. C. Doherty and A. Kelso, "Toward a broadly protective influenza vaccine," Journal of Clinical Investigation, vol. 118, no. 10, pp. 3273-3275, 2008.

[28] A. J. McMichael and T. Hanke, "HIV vaccines 1983-2003," Nature Medicine, vol. 9, no. 7, pp. 874-880, 2003.

[29] M. Chen, M. Sällberg, A. Sönnerborg et al., "Limited humoral immunity in hepatitis C virus infection," Gastroenterology, vol. 116, no. 1, pp. 135-143, 1999.

[30] D. Yerly, D. Heckerman, T. M. Allen et al., "Increased cytotoxic T-lymphocyte epitope variant cross-recognition and functional avidity are associated with hepatitis C virus clearance," Journal of Virology, vol. 82, no. 6, pp. 3147-3153, 2008.

[31] M. Han, S. Watarai, K. Kobayashi, and T. Yasuda, "Application of liposomes for development of oral vaccines: study of in vitro stability of liposomes and antibody response to antigen associated with liposomes after oral immunization," Journal of Veterinary Medical Science, vol. 59, no. 12, pp. 1109-1114, 1997.

[32] S. Watarai, M. Han, Tana, and H. Kodama, "Antibody response in the intestinal tract of mice orally immunized with antigen associated with liposomes," Journal of Veterinary Medical Science, vol. 60, no. 9, pp. 1047-1050, 1998.

[33] C. M. Snapper and J. J. Mond, "Towards a comprehensive view of immunoglobulin class switching," Immunology Today, vol. 14, no. 1, pp. 15-17, 1993.
[34] A. Casadevall, "Antibody-mediated immunity against intracellular pathogens: two-dimensional thinking comes full circle," Infection and Immunity, vol. 71, no. 8, pp. 4225-4228, 2003.

[35] A. Casadevall and L. A. Pirofski, "A reappraisal of humoral immunity based on mechanisms of antibody-mediated protection against intracellular pathogens," Advances in Immunology, vol. 91, pp. 1-44, 2006.

[36] E. de Gregorio, E. Tritto, and R. Rappuoli, "Alum adjuvanticity: unraveling a century old mystery," European Journal of Immunology, vol. 38, no. 8, pp. 2068-2071, 2008.

[37] E. B. Lindblad, "Aluminium compounds for use in vaccines," Immunology and Cell Biology, vol. 82, no. 5, pp. 497-505, 2004.

[38] A. M. Harandi, D. Medaglini, and R. J. Shattock, "Vaccine adjuvants: a priority for vaccine research," Vaccine, vol. 28, no. 12, pp. 2363-2366, 2010.

[39] S. L. Hem and J. L. White, "Structure and properties of aluminum-containing adjuvants," Pharmaceutical Biotechnology, vol. 6, pp. 249-276, 1995. 

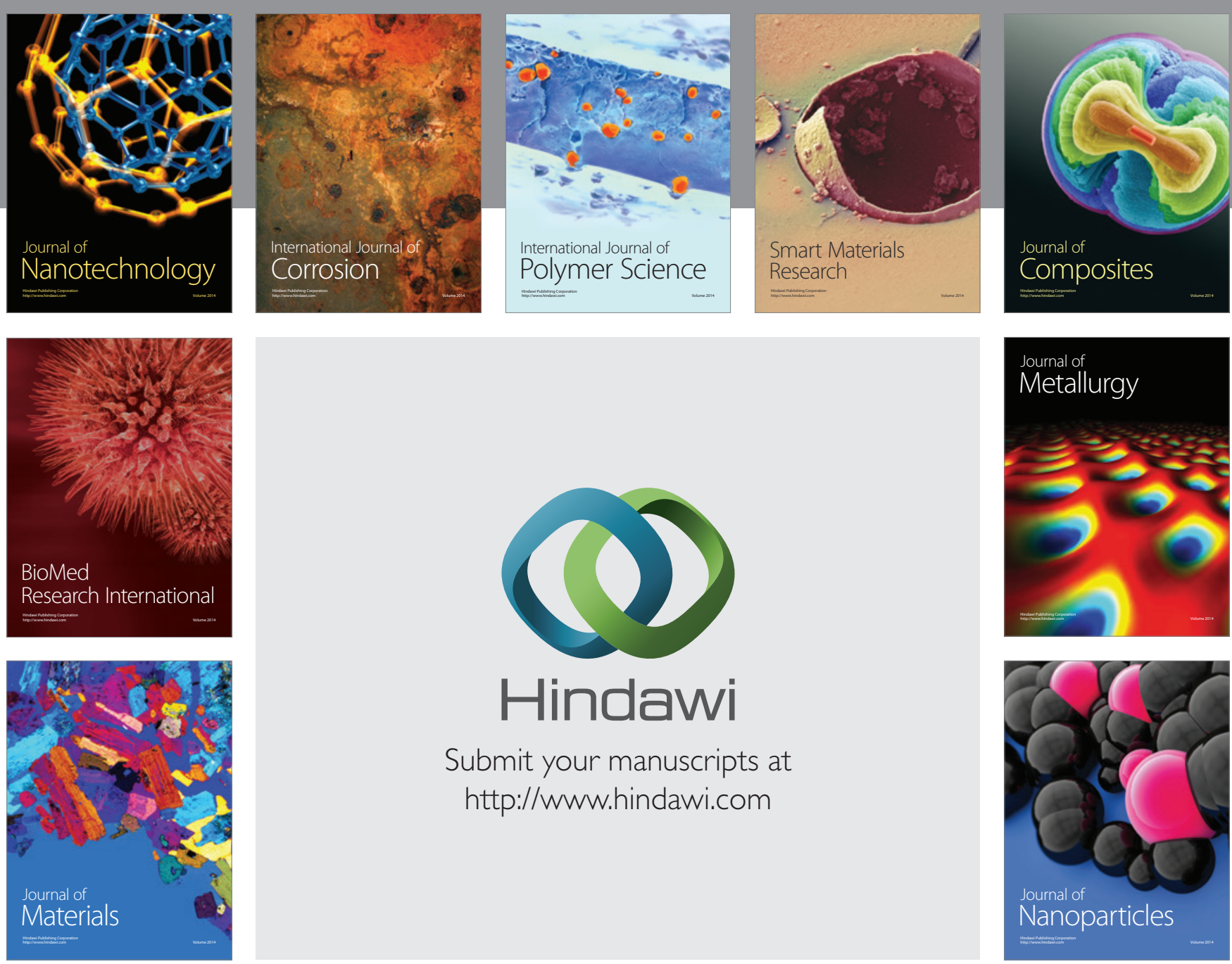

Submit your manuscripts at http://www.hindawi.com
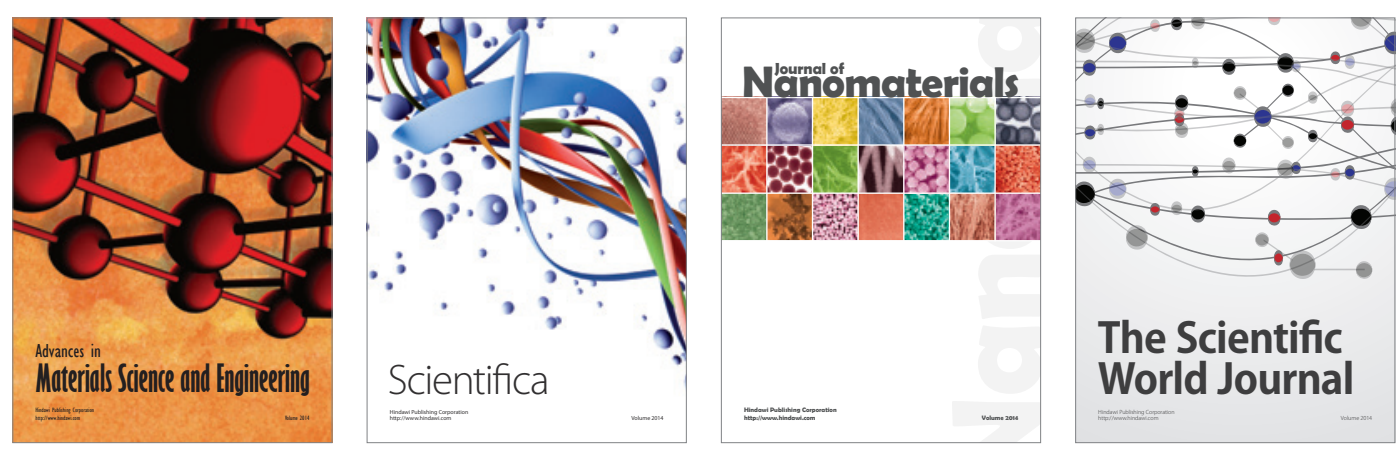

\section{The Scientific World Journal}
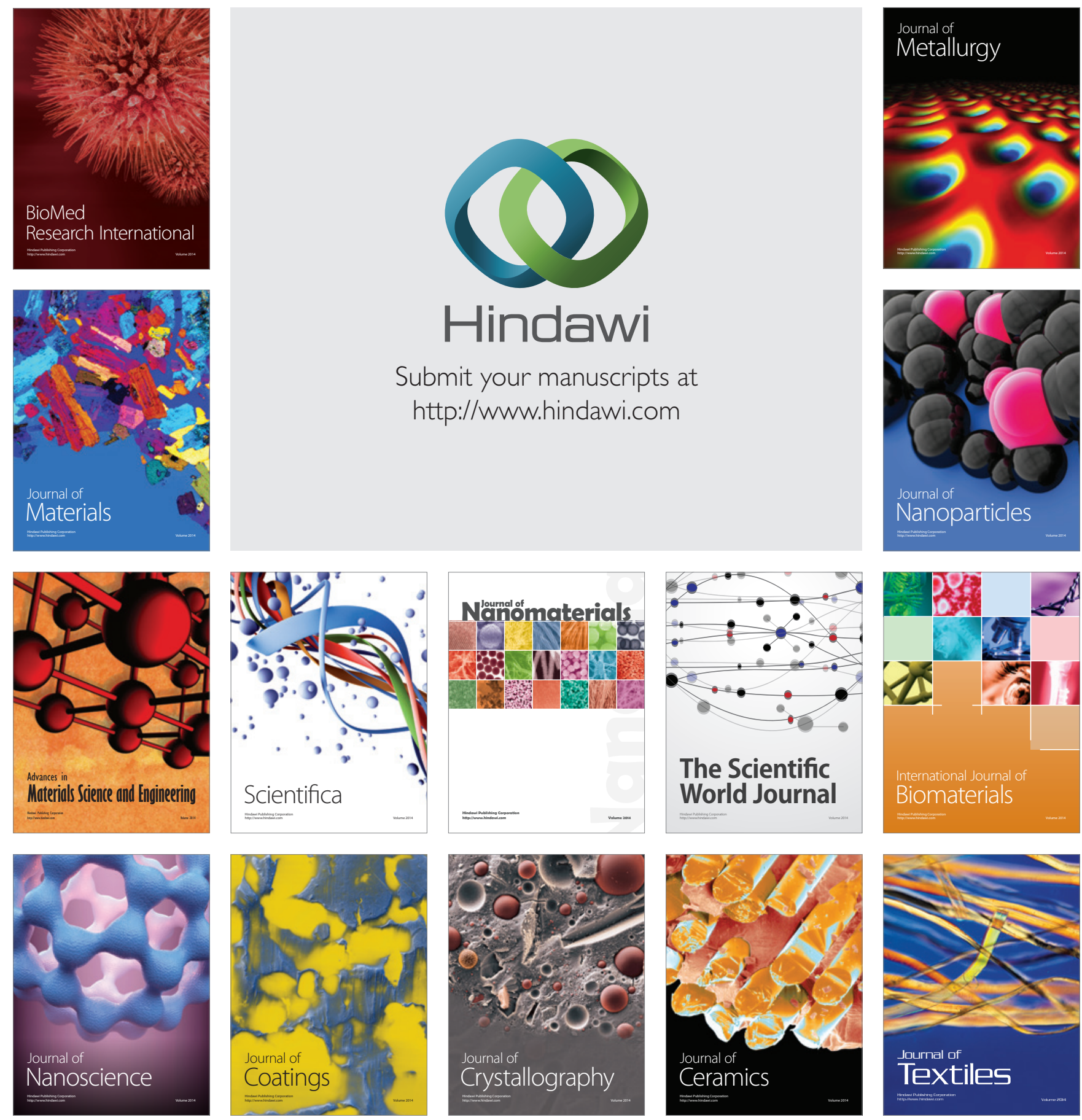